\title{
Correction to: Imported and autochthonous malaria in West Saudi Arabia: results from a reference hospital
}

Rasha Hassan Soliman 1,2, Patricia Garcia-Aranda ${ }^{3}$, Sherine Mohamed Elzagawy ${ }^{2,4}$, Boshra El-Sayed Hussein ${ }^{5,6}$, Wael Wahid Mayah ${ }^{5,7}$, Alexandra Martin Ramirez ${ }^{3}$, Thuy-Huong Ta-Tang ${ }^{3}$ and José Miguel Rubio ${ }^{3^{*}}$ (1)

\section{Correction to: Malar J (2018) 17:286}

https://doi.org/10.1186/s12936-018-2438-7

Following publication of the original article [1], it was flagged by one of the authors that the name of the P. falciparum gene marker of artemisinin resistance 'pfkelch13' was (incorrectly) written as "pfketch13", which was repeated seven times in different parts of the published paper.

As such, please note that "pfketch13" in the article [1] should in fact be pfkelch13.

\section{Author details}

${ }^{1}$ Microbiology Department, Faculty of Medicine, Taif University, Al Hawiyah, Taif, Kingdom of Saudi Arabia. ${ }^{2}$ Parasitology Department, Faculty of Medicine, Suez Canal University, Ismailia, Egypt. ${ }^{3}$ Malaria and Emerging Parasitic Diseases Laboratory, National Microbiology Centre, Instituto de Salud Carlos III, Madrid, Spain. ${ }^{4}$ Princes Nourah Bint Abdulrahman University, Riyadh, Kingdom of Saudi Arabia. ${ }^{5}$ Department of Tropical Medicine and Infectious Diseases, Faculty of Medicine, Tanta University, Tanta, Egypt. ${ }^{6}$ King Faisal Medical Complex, Taif, Kingdom of Saudi Arabia. ${ }^{7}$ Faculty of Dentisary, King Abdulaziz University, Jeddah, Kingdom of Saudi Arabia.

The original article can be found online at https://doi.org/10.1186/s1293 6-018-2438-7.

\section{Publisher's Note}

Springer Nature remains neutral with regard to jurisdictional claims in published maps and institutional affiliations.

Published online: 20 September 2018

\section{Reference}

1. Soliman RH, Garcia-Aranda P, Elzagawy SM, Hussein BE, Mayah WW, Martin Ramirez A, Ta-Tang T-H, Rubio JM. Imported and autochthonous malaria in West Saudi Arabia: results from a reference hospital. Malar J. 2018;17:286. https://doi.org/10.1186/s12936-018-2438-7.

\footnotetext{
*Correspondence: jmrubio@isciii.es

${ }^{3}$ Malaria and Emerging Parasitic Diseases Laboratory, National

Microbiology Centre, Instituto de Salud Carlos III, Madrid, Spain

Full list of author information is available at the end of the article
} 